\title{
Urdimento
}

Revista de Estudos em Artes Cênicas

E-ISSN: 2358.6958

\section{Do Drama Musical à Imersão: Notas sobre a "arte total" contemporânea e latino-americana}

Patrícia Teles Sobreira de Souza

\section{Para citar este artigo:}

SOUZA, Patrícia Teles Sobreira de. Do Drama Musical à Imersão: Notas sobre a "arte total" contemporânea e latino-americana. Urdimento, Florianópolis, v. 2, n. 38, ago./set. 2020.

DOI: http:/dx.doi.org/10.5965/14145731023820200012

Este artigo passou pelo Plagiarism Detection Software | iThenticate 
Do Drama Musical à Imersão: Notas sobre a "arte total" contemporânea e latino-americana

Patrícia Teles Sobreira de Souza ${ }^{1}$

\begin{abstract}
Resumo
O artigo debruça-se sobre a noção de obra-de-arte-total wagneriana aplicada à Arte Contemporânea. Desta forma, versa sobre o imbricamento das linguagens performativas e visuais e a dissolução da fronteira entre palco e plateia por meio da integração do espaço, de modo a fomentar a imersão do espectador. Neste contexto, diferente da relação ator-espectador, o jogo teatral é agenciado pela dinâmica espaço-espectador. Por fim, analisa trabalhos de artistas latino-americanos, entre eles, Diego Bianchi, Marta Minujín e Tania Bruguera.
\end{abstract}

Palavras-chave: Arte contemporânea. Espaço. Espectador.

\title{
From Music Drama to Immersion: Notes on contemporary and Latin American "total art"
}

\begin{abstract}
The article focuses on the Wagner's concept of Gesamtkunstwerk applied to Contemporary Art. Therefore, it deals with the interweaving of performative and visual languages and the dissolution of boundaries between stage and audience through the integration of space, in order to foster the viewer's immersion. In this way, different from the actor-spectator relationship, the theatre play is guided by the dynamics space-spectator. Finally, it analyzes works by Latin American artists, including Diego Bianchi, Marta Minujín and Tania Bruguera.
\end{abstract}

Keywords: Contemporary art. Space. Spectator.

Doutoranda em Artes (UnB); Mestrado na Universidad Nacional de las Artes (Buenos Aires, 2016. Em 2019 foi selecionada para participar do SACO 8 (Festival de Arte Contemporáneo en Chile) e do II Prêmio Vera Brant (Brasília, DF). patriciateles86@gmail.com 
Del Drama Musical a la Inmersión: Notas acerca del "arte total" contemporáneo y latinoamericano

\section{Resumen}

El artículo se centra en la noción de obra-de-arte-total wagneriana aplicada al arte contemporáneo. De esta manera, discurre acerca del entrelazamiento de los lenguajes performativos y visuales y de la disolución del límite entre escena y audiencia, por medio de la integración del espacio, para fomentar la inmersión del espectador. En este contexto, a diferencia de la relación actor-espectador, el juego teatral se guía por la dinámica espacio-espectador. Por fin, analiza obras de artistas latinoamericanos, entre ellos, Diego Bianchi, Marta Minujín y Tania Bruguera.

Palabras-clave: Arte contemporáneo. Espacio. Espectador. 


\section{A obra-de-arte-total e seus desdobramentos na arte contemporânea}

Há uma ideia de espetáculo integral que devemos fazer renascer.

o problema é fazer o espaço falar, alimentá-lo e mobiliá-lo.

(Artaud, 1984, p.125)

O conceito de "obra-de-arte-total", a Gesamtkunstwerk, nos remete ao século XIX, onde, pela primeira vez, o cruzamento intencional de linguagens artísticas foi teorizado ${ }^{2}$ pelo compositor Richard Wagner. No tratado A Obra de Arte do Futuro (1849), Wagner defende a constituição de uma obra de arte "universal" em detrimento de uma obra erudita e elitista. Essa obra se expressa por meio do "drama" que, segundo Wagner (2000, p.143), é a "mais alta obra de arte". Deste modo, somente o drama seria capaz de transmitir a "suprema plenitude da essência humana" (Wagner, 2000, p.152). Wagner refere-se ao "drama musical", que assim como as tragédias gregas, deve representar mitos de interesse da vida pública e coletiva. (Barrio, 2013).

Embasado na arte da Grécia Antiga, Wagner discorre sobre a confluência de três modalidades artísticas "puramente humanas": a dança, a música e a poesia. Justapostas de modo deshierarquizado ${ }^{3}$, essas três artes "irmãs" alcançariam seu desenvolvimento máximo. Por outra parte, o autor versa sobre as artes plásticas, que, diferente das humanas, dependem da materialidade dos "objetos da natureza”. São elas: arquitetura, escultura e pintura. Neste âmbito, a justaposição das modalidades humanas e plásticas compõem a "obra de arte do futuro".

Neste contexto, Wagner propõe um resgate da coletividade em oposição a arte "egoísta” e "elitista”, apreciada por aqueles que possuem "erudição artística”,

\footnotetext{
2 Allan Kaprow (1993, p.10), no artigo, Notas para Criação da Arte Total (Notes on the Creation of Total Art), publicado originalmente em 1958, observa que: [...] with the advent of the Renaissance, an emphasis on unique personal styles led to more specialization. Conscious thoughts about a total art did not emerge until Wagner [...]" - [...] com a emergência do Renascimento, a ênfase em estilos pessoais e únicos culminou em uma maior especialização. Um pensamento consciente sobre a arte total não emergiu até Wagner [...]. (Tradução nossa).

${ }^{3}$ Segundo Wagner (2000, p.110), a "obra de arte do futuro" deve estabelecer o equilíbrio entre as artes irmãs. Diferente, por exemplo, da ópera, em que ocorre "uma egoísta autoglorificação da música”.
} 
e, portanto, que estava afastada da vida do povo. Por conseguinte, arquitetos e pintores deveriam trabalhar o espaço do teatro para receber ao "ser humano artista”, uma visão ideológica da obra pictórica, na qual o papel do pintor é revisto.

[...] había comprimido hasta ese instante en el estrecho marco de un cuadro - que el colgaba en la pared de la solitaria habitación del egoísta, o que entregaba para que, expuesto en una galería, se deformase, entre otros muchos cuadros con los que no guardaba relación ni formaba unidad - hará ahora que llene el amplio marco del teatro trágico, configurando todo el espacio del escenario como prueba de su fuerza creadora natural. (Wagner, 2000, p.145).

As teorias de Wagner correspondem a um contexto específico, o artista foi militante político e atuou diretamente nas Revoluções de 1848 dos Estados Alemães. Por essa razão, Wagner vislumbrava uma arte que engajasse as massas, um teatro idealizado para representar a unificação dos estados alemãs e seu ideal democrático. Foi durante o exílio na Suíça que o artista escreveu seus tratados, em Arte e Revolução (1849), o compositor identifica na "separação das artes" o desmantelamento do propósito político e público da arte.

Con la decadencia de la tragedia, el arte dejó para siempre de ser la expresión de la conciencia pública. El drama se disolvió en sus elementos constitutivos: la retórica, la escultura, la pintura, la música, etc., abandonaron la unidad para seguir cada una su propio camino, desde la independencia, la soledad y el egoísmo. (Wagner, 2013, p. 47).

Sem embargo, apesar da conjuntura histórica germânica do século XIX, e do espírito romântico, nacionalista e antissemita do compositor, nos interessa pensar o pioneirismo de Wagner em conceitualizar a confluência entre as linguagens "humanas" e "plásticas" em prol de uma "arte total”. Posteriormente, no século XX, a Gesamtkunstwerk wagneriana torna-se referente conceitual de artistas que buscam cruzar, de modo deshierarquizado, as linguagens artísticas.

A esse respeito, Rita Eder (2014) pontua alguns marcos do paradigma da "obra-de-arte-total" na vanguarda europeia, a autora destaca o enfoque arquitetônico da Bauhaus, onde "Walter Gropius, su director, intentaba reunir los esfuerzos creativos en un todo, reunificar todas las disciplinas, la escultura, la 
pintura, las artesanías, como componentes inseparables de una nueva arquitectura" (Eder, 2014, p.70). E por outro lado a defesa da "união das artes" em Wassily Kandinsky, expresso no texto Do Espiritual na Arte (1912).

A autora sinaliza os sintomas da Gesamtkunstwerk wagneriana em Gropius e Kandinsky para identificar as influências da "arte total" na América Latina, mas precisamente no México, onde reconhece no Teatro Pánico de Alejandro Jodorowsky e no Museu Experimental El ECO - idealizado pelo artista plástico alemão Mathias Goeritz e fundado em 1953 na Cidade do México - dois aspectos do "total" na arte contemporânea mexicana.

Em vista disso, cabe ressaltar que a concepção de uma "arte total" no contexto da arte contemporânea não está vinculada ao caráter absoluto do drama, como observa Luiz Fernando Ramos (2015) ao sinalizar que Wagner "pode ser um marco referencial negativo" no que diz respeito à "ilusão de verossimilhança na representação realista" (Ramos, 2015, p. 173). Isto porque, de modo geral, as produções contemporâneas são antiteatrais, no sentido adotado pelo pesquisador de rechaço a "qualquer estrutura narrativa encadeada, ou, em síntese, ao dramático como estratégia instrumental para engajar o observador" (Ramos, 2015, p.33). Neste âmbito, Boris Groys (2008) informa essa ressignificação da noção de totalidade wagneriana:

En la terminología actual, el concepto de "Gesamtkunstwerk" corresponde, más que nada, el concepto de multimedialidad, que designa la utilización de diferentes medios en el marco de una misma obra de arte. Así, en la ópera, la música, el texto, la actuación y la escenografía se integran en una obra de arte única, total, que, como esperaba Wagner, puede resultar capaz de someter completamente la percepción y la imaginación del espectador. (Groys, 2008, p. 12).

Por conseguinte, a "arte-total" esta relacionada à simbiose das artes, ao desmantelamento das fronteiras entre gêneros que, entre outros fatores, culminou no desenquadramento da pintura e a subtração do pedestal escultórico em prol da conquista do espaço teatralizado e fenomenológico, o qual "não é um ambiente (real ou lógico) em que as coisas se dispõem, mas o meio pelo qual a posição das coisas se torna possível." (Merleau-Ponty, 2018, p. 328). Sendo assim, 
um espaço que depende da experiência do "sujeito-perceptivo", em outras palavras, do espectador.

Contudo, Groys (2018) considera que a multisensorialidade da obra-total pode resultar capaz de privar o espectador de um distanciamento crítico. Por outra parte, fundamentados na fenomenologia de Merleau-Ponty, afirmamos que é o espectador quem torna o espaço possível. Desta forma, podemos indagar: como a obra-total pode "someter a percepção e imaginação" do espectador, se é ele, o sujeito-perceptivo, quem traça o espaço?

Em Fenomenologia da Percepção, Merleau-Ponty (2018, p. 329) descreve o experimento de utilizar óculos que "viram para baixo as imagens retinianas", segundo o filósofo, "no final da experiência, [...] as reações motoras estão invertidas: o paciente estende a mão direita quando seria preciso estender a esquerda" (Merleau-Ponty, 2018, p. 330). Assim, de modo análogo ao experimento citado, podemos pensar que o espectador ao mesmo tempo que cria o mundo "invertido" e afetado por ele.

No contexto cênico, abre-se outra vertente, na qual a essência da teatralidade, comumente pautada na relação ator-espectador ${ }^{4}$, é trasladada para a dinâmica espaço-espectador, visto que é o ambiente penetrável ${ }^{5}$ que baliza o jogo com o público. Tomemos como exemplo o conceito de instalação total de Ilya Kabakov, no qual o artista propõe:

Establecer conexiones con el otro lado de las fronteras de cada tipo de arte, seguir el camino de la "interdisciplinariedad", acercando y tendiendo puentes entre lo que hasta ahora había estado divorciado, música, poesía, literatura, teatro, artes plásticas, todo dentro de los límites del nuevo "territorio" del espacio artístico. Estamos hablando de un intento concreto de crear una nueva "Gesamtkunstwerk". (Kabakov, 2014, p. 28).

\footnotetext{
${ }^{4}$ Evréinov afirma que a teatralidade do teatro repousa essencialmente sobre a teatralidade do ator [...]. (Féral, 2015, p. 90).

5 Emprega-se o termo "penetrável" como sinônimo de imersão corporal em um ambiente e não, necessariamente, no sentido de absorção intelectual do espectador. Diferentemente de uma sensação psíquica, o penetrar refere-se a uma dimensão material, palpável, sendo assim, compreende-se que o espectador está "imerso" quando todo seu corpo esta situado dentro de um enquadramento, de uma demarcação sensível que corresponde o espaço do trabalho artístico.
} 
Na instalação-total, The Man Who Flew Into Space From His Apartment [0 Homem que voou para o Espaço do seu Apartamento] (1984), os visitantes entram em um primeiro ambiente onde estão expostos, entre outros objetos, documentos e testemunhos prestados à polícia de três companheiros de apartamento do protagonista da cena (o homem que voou para o espaço). Os documentos relatam a versão de cada um deles acerca do incidente ocorrido. Desde esta primeira sala, os visitantes podem ver os vestígios do feito (Figura 1), uma encenação que ocorre não por corpos de atuantes, mas por meio da instalação dos objetos no espaço. Um quarto com artigos desordenados, diversos cartazes colados na parede, jornais, desenhos, uma cama, uma catapulta, escombros e um buraco no teto. Altamente teatralizada, a instalação total de Kabakov é uma cena cujos corpos que atuam são os corpos dos visitantes.

Por meio de uma narrativa ficcional, o artista apresenta um desejo utópico de escapar da realidade que o circunda e revela traços autobiográficos de um cidadão russo inserido na conjuntura soviética da Corrida Espacial. Segundo Boris Groys (2008), Kabakov é um dos artistas representantes do "pós-utopismo", que emerge na Rússia nos anos 1970 em decorrência da desconstrução dos princípios da vanguarda formalista, e de sua "antítese", o "realismo socialista" imposto por Josef Stalin. ${ }^{6}$

Em resumo, a arte soviética pós-utópica se estabelece na desconfiança do mito vanguardista, e no "regreso a la narratividad, que se opone a la renuncia de la vanguardia a toda literalidad" (Groys, 2008, p. 179). Filia-se, portanto, ao caráter mimético do "realismo socialista", não obstante, a partir de outra perspectiva, não mais vinculada à propaganda política de manutenção do poder, mas, de uma “lógica de inclusão” e de caráter reflexivo.

\footnotetext{
${ }^{6}$ Groys (2008, p.13) compreende que, "la realidad soviética de la época estaliniana puede ser descrita como una única escenificación multimedia: como una obra de arte total, capaz de absorber e incorporar completamente dentro de sí a su espectador." Deste modo, durante o regime "estético" de Stalin, "la única obra de arte cuya creación estaba autorizada: el socialismo, [...] la única poética necesaria: la poética de la construcción del mundo nuevo." (Groys, 2008, p. 84).
} 
Figura 1 - Ilya Kabakov, The Man Who Flew Into Space From His Apartment (1984)

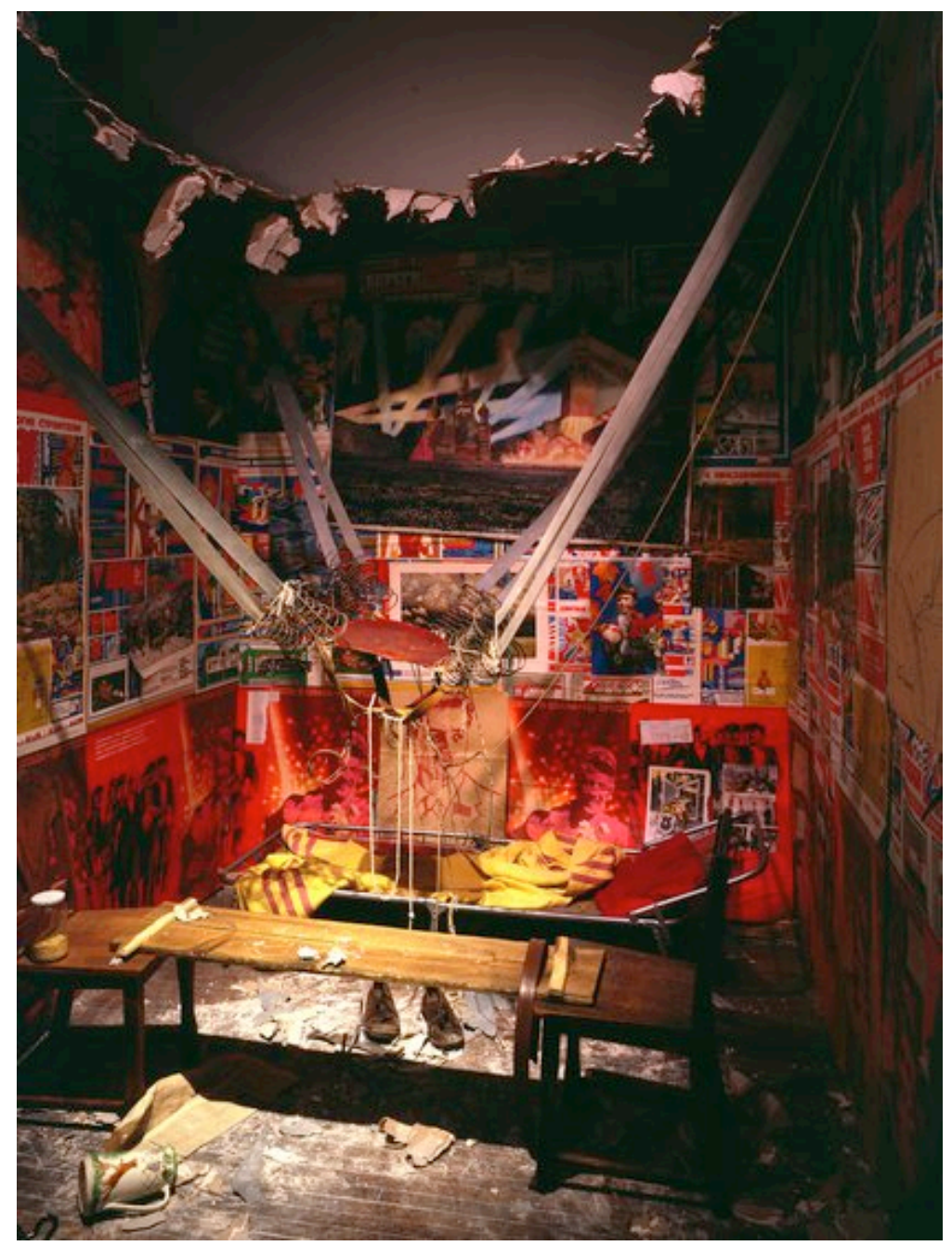

Fonte: https://www.tate.org.uk/whats-on/tate-modern/exhibition/ilya-and-emilia-kabakov Acesso em: 24 jun. 2020.

Groys (2015, p. 211) refere-se à assimilação dos símbolos do capitalismo ocidental pelos artistas soviéticos não-oficiais, dentre eles Kabakov, que propõem um projeto de "reconciliação ideológica". Em vista disso, destaca-se na poética de Kabakov o uso de significantes que provocam um "estranhamento" no espectador, já que, não se trata de uma narrativa de sentido único em prol de um discurso totalitário, mas de uma composição espacial que comenta a si mesma.

Destarte, cabe frisar a subversão do ideal de 'totalidade' wagneriana na prática de Kabakov. Wagner compreende que o público deve se identificar com o mito representado, para tanto, é preciso o envolvimento emocional do espectador, 
onde a interferência do mundo imediato poderia distanciá-lo da narrativa mimética. Diferente de Wagner, Kabakov (2014, p. 14) considera que "el espectador no debe olvidar que ante él hay un engaño y que todo se ha hecho “intencionalmente", especialmente, con el fin de crear una impresión.” Sendo assim, o foco não está na emoção, mas na percepção do espectador.

Desta forma, o ambiente imersivo teatralizado apresenta uma dinâmica distinta do jogo pautado na relação ator-espectador. Kabakov não emprega atores em suas composições, toda narrativa ficcional se desenvolve no ambiente a medida em que o espectador avança pelo espaço cênico. Por conseguinte, a trama se desvela na ação do espectador de explorar e semiotizar o ambiente ao seu redor. Assim, a imersão do espectador em The Man Who Flew Into Space From His Apartment joga com essa dupla camada, tanto sensível como interpretativa, como sinaliza Claire Bishop (2005, p. 14): "a ideia de 'instalação total' proporciona um modelo muito particular de experiência - que não apenas imerge fisicamente o espectador em um espaço tridimensional, mas que também o absorve psicologicamente [...]". ' Isto posto, pontua-se a imersão do público como sintoma da apropriação contemporânea da Gesamtkunstwerk, onde o coração do projeto teatral não se encontra na relação de troca entre atores e espectadores, mas no ambiente sensorial e simbólico. O espaço torna-se o cerne do trabalho cênico e o público é convidado a descobri-lo.

\section{A dissolução da dualidade palco-plateia}

A conceptualização da arte revolucionária de Wagner propõe o arrebatamento do espectador por meio da ilusão, da catarse coletiva, reforça assim a separação do edifício teatral em dois universos: palco e plateia. Neste intuito, o compositor é o primeiro a apagar as luzes do auditório:

Em 1876, Richard Wagner (1813-1883) apaga as luzes da plateia durante a

the idea of the 'total installation' offers a very particular model of viewing experience - one that not only physically immerses the viewer in a three-dimensional space, but which is psychologically absorptive too [...]. (Bishop, 2005, p. 14). (Tradução nossa). 
apresentação de suas óperas, em Bayreuth, rompendo uma tradição que vinha desde a Renascença; em pouco tempo, outros teatros farão o mesmo. A sala no escuro traz um envolvimento maior do espectador com a cena, reforçando a ideia de ilusão. A ribalta abre uma fronteira entre o drama e o espectador, reforçando a ação restritiva do quadro cênico e contribuindo para o seu afastamento. Por outro lado, o escurecimento da plateia contraria o hábito do público de ir ao teatro para se mostrar. Nesse momento, "o teatro deixa de ser o imenso salão da sociedade burguesa". (Camargo, 2012, p. 17-18).

No contexto da Arte Contemporânea, diferente de Wagner - que promove o apagamento da plateia pretendendo abafar o "exibicionismo burguês" e direcionar a atenção do público para o palco - os artistas deslocam o espectador para dentro da cena. Logo, desfeita a dualidade entre palco e plateia - esse "corpo orgânico composto de dois órgãos que funcionam um em relação ao outro: a sala e a cena" (Ortega y Gasset, 2014, p. 32) - efetiva-se a imersão corpórea do público. Por meio da confluência dos espaços, palco e plateia tornam-se um ambiente único, todo ele constituído pela cena.

No século XX, os modos de ruptura da dualidade palco e plateia foram debatidos por artistas que buscavam renovar as práticas teatrais. Neste âmbito, Antonin Artaud foi um dos precursores a teorizar a dissolução da demarcação do espaço da ação e do espaço da contemplação. No primeiro manifesto do Teatro da Crueldade (1932), Artaud afirma que:

será estabelecida uma comunicação direta entre o espectador e o espetáculo, entre ator e espectador, pelo fato de o espectador, colocado no meio da ação, estar envolvido e atravessado pela ação. Este envolvimento provém da própria configuração da sala. (Artaud, 1984, p. 123).

Inspirado no Teatro da Crueldade, Alejandro Jodorowsky idealiza o Teatro Pánico. No texto, Hacia el efímero pánico o isacar el teatro del teatro! (1965), Jodorowsky defende que

es preciso liberar-se del edificio teatro, antes que nada. Arquitecturalmente, tomen las formas que tomen, los teatros son concebidos para actores y espectadores; obedecen a la ley primordial del 
juego que es cercar un espacio lúdico [...]. (Jodorowsky, 1981, p. 6)

Segundo Eder (2014), o teatro de Jodorowsky é um referente da emergência da "obra total" no México, sendo assim, destaca-se no contexto latino-americano a assimilação da totalidade vinculada à "eliminação da audiência" em prol da "festa espetáculo" (Jodorowsky, 1981).

Em, Notes on the Elimination of the Audience [Notas sobre a eliminação da Plateia] (1966) Allan Kaprow, idealizador dos Happenings e dos Environments, aponta para dificuldade da cena contemporânea em superar a disposição convencional que separa a audiência do acontecimento cênico: “[...] por mais flexíveis que sejam essas técnicas na prática, sempre havia um público em um espaço (geralmente estático) e a 'performance' em outro" (Kaprow, 2006, p.102)8. Disposto a romper esse paradigma, Kaprow realizou happenings onde todo espaço era espaço de ação, sendo o público confrontado diretamente, não somente pela ausência de uma quarta parede, mas pela dissolução do palco.

Outro referente é o encenador polonês Jerzy Grotowski, idealizador do Teatro Pobre, conceito que define a prática de retirar da encenação tudo o que pode ser considerado supérfluo (maquiagem, cenário, figurino, efeitos sonoros e luminosos, entre outros). Nesta subtração gradativa dos elementos que constituem a cena, Grotowski concluiu que o teatro só não pode existir sem o relacionamento atorespectador: "podemos então definir o teatro como 'o que ocorre entre o espetador e o ator'. Todas as outras coisas são suplementares" (Grotowski, 1992, p.28). Destaca-se em sua prática a composição de um espaço único, no qual atores e espectadores ocupam o mesmo lugar, a cena.

Por exemplo, Kordian (1962), realizado em um manicômio, foi encenado em uma grande sala em que as camas de dois andares foram distribuídas irregularmente; os membros da plateia sentavam-se em algumas camas, enquanto outras eram usadas por atores-pacientes, a ação, realizada em torno das camas, colocava os espectadores no meio dela, permitindo que funcionassem como internos passivos ou observadores. (Brockett et al.,

8 [...] however flexible these techniques were in practice, there was always an audience in one (usually static) space and a show given in another. (Kaprow, 2006, p.102). (Tradução nossa) 


$$
\text { 2017, p. 217). }{ }^{9}
$$

A dinâmica entre ator-espectador como alicerce da cena teatral é igualmente enfatizada por Josette Féral, a pesquisadora considera que:

os sistemas significantes - espaço cenográfico, figurinos, maquiagem, narração, texto, iluminação, acessórios - podem desaparecer sem que a teatralidade cênica seja profundamente afetada. É suficiente que o ator permaneça para que a teatralidade seja preservada e o teatro possa acontecer, prova que o ator é um dos elementos indispensáveis à produção da teatralidade cênica. (Féral, 2015, p. 91).

Féral nos lembra que os atores podem ser entendidos em um contexto amplo, como marionetes ou objetos animados. Por outra parte, as produções artísticas que investem na transdisciplinaridade da "arte total" apontam para uma teatralidade cênica na qual os atores seriam dispensáveis, cabendo aos espectadores o papel de atuantes. Isto porque, uma vez imersos no perímetro que agencia a suspensão da lógica cotidiana, o espaço do jogo ${ }^{10}$, o público torna-se, involuntariamente, sujeitos em cena. Neste sentido, os atores perdem o protagonismo do acontecimento engendrado, tornam-se elementos que compõem o ambiente a ser explorado e semiotizado pelo espectador. Em outras palavras, o espaço não está em função do ator, mas, ao contrário, é o ator quem atua em função do espaço.

\section{A Gesamtkunstwerk latino-americana}

A seguir, serão descritos e analisados quatro trabalhos de artistas latinoamericanos que agenciam a imersão do espectador no espaço teatralizado. São eles, La Menesunda (1965-2016) de Marta Minujín e Rubén Santantonín, Fiat Lux: o

${ }^{9}$ For example, Kordian (1962), which takes place in a insane asylum, was staged in a large room throughout which double-decker beds were spaced irregularly; audience members sat on some of the beds, whereas others were used by actors-patients, and the action, which took place in around beds, placed the spectators in its midst, allowing them to function as passive inmates or observers. (Brockett e col., 2017, p. 217). (Tradução nossa)

${ }^{10}$ Compreende-se como jogo a prática teorizada por Huizinga (2018, p. 11), que afirma que "o jogo distingue-se da vida 'comum', tanto pelo lugar, como pela duração que ocupa." 
Sermão da Montanha (1979) de Cildo Meireles, Sin Titulo (Habana, 2000) (2000 2018) de Tania Bruguera e Under de Sí(2013) de Diego Bianchi e Luis Garay. Os trabalhos possuem em comum a perspectiva de uma "obra total", que emerge do cruzamento deshierarquizado das linguagens "plásticas" e "humanas", na construção de ambientes penetráveis e multissensoriais que incorporam a performatividade dos espectadores como significantes do trabalho. Ressalta-se assim a ênfase na relação do espectador com o espaço em detrimento da performance do ator.

\section{La Menesunda - Marta Minujín e Rubén Santantonín}

La Menesunda foi exibida pela primeira vez em 1965 no Instituto Di Tella na capital portenha e, posteriormente, reconstruída em 2016 no MAMBA - Museu de Arte Moderna de Buenos Aires. Consiste em um "labirinto ultrasensorial" que deve ser percorrido pelo público, passando por diversos ambientes: um túnel com luzes neon; um corredor com circuito fechado de televisão, no qual os visitantes podem ver a si mesmos nas telas dos monitores; um quarto privado onde um casal, de pijamas, se encontra deitado em uma cama; um espaço com maquiadoras que maquiam e massageiam os passantes; outro ambiente repleto de estumas, simbolizando um intestino gigante; um branco e gélido ambiente que simula o interior de uma geladeira; entre outros. Por último, um espaço repleto de espelhos, confetes e ventiladores que marca o fim do recorrido ${ }^{11}$.

${ }^{11}$ Vídeo registro de La Menesunda (MAMBA, 2016): < https://youtu.be/e90D5Co3km4 >. Acesso em: 24 jun. 2020. 
Figura 2 - Marta Minujín e Rubén Santantonín, La Menesunda (1965)
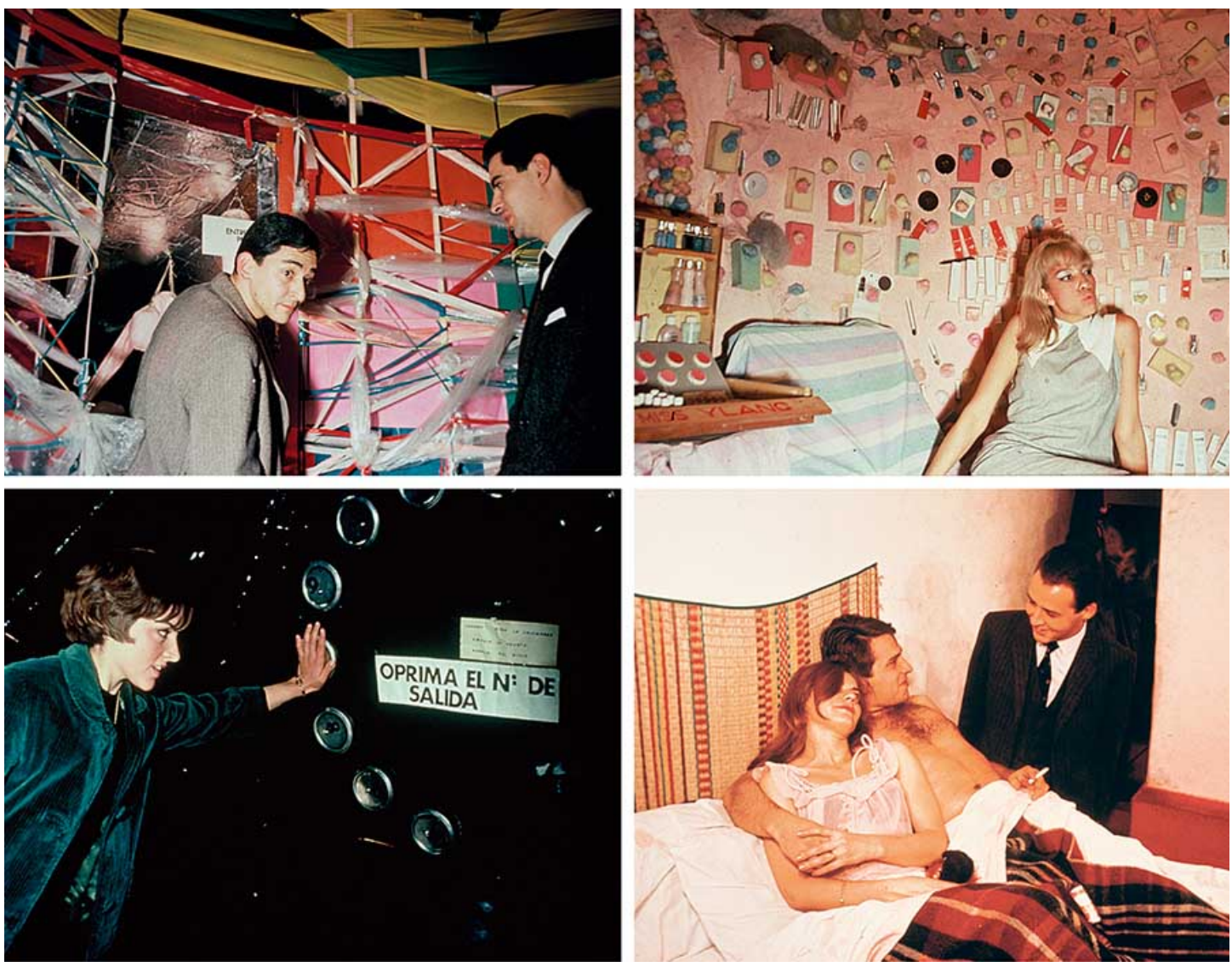

Fonte: https://arteref.com/instalacao/conheca-sobre-a-instalacao-argentina-lamenesunda/. Acesso em: 24 jun. 2020

Segundo Minujín (2015, p. 69), trata-se de "una obra que no tiene un espacio, porque no es un género y, entonces, para que exista hay que inventarle un espacio." Em La Menesunda, Minujín e Santantonín apropriam-se os estímulos da capital portenha e do fluxo urbano industrial na construção de um ambiente imagético e relacional. A inspiração para o trabalho foi a Calle Lavalle, no Centro Histórico de Buenos Aires, logo, os artistas ressignificam o espaço urbano cotidiano trasladando-o para o contexto artístico.

Minujín, entre outras coisas, é conhecida por introduzir a Arte Pop na Argentina, logo, apropria-se dos símbolos do cotidiano e da cultura de massa na composição de seus trabalhos. Neste âmbito, Minujín e Santantonín são pioneiros em direcionar a estética pop para experiência imersiva e sensorial do público. No lugar do objeto escultórico e da imagem bidimensional, os artistas argentinos 
investem no acontecimento teatral que entrelaça artes plásticas e artes do espetáculo. Em menor escala, Warhol irá propor essa dinâmica relacional com os espectadores em 1966, com a instalação Silver Clouds ${ }^{12}$.

La Menesunda não se inscreve em um paradigma social da arte, não obstante, não deixa de ser política, por "ironizar a distinção entre arte elevada e arte popular" (Danto, 2018, p. 21). Ademais, preconiza na Argentina a noção de "arte total", onde pintura, escultura, teatro e mídias tecnológicas se cruzam de modo deshierarquizado, proporcionando ao espectador um olhar desautomatizado sobre a metrópole e seu próprio corpo.

\section{Fiat Lux: O Sermão da Montanha - Cildo Meireles}

Já Cildo Meireles, em Fiat Lux: O Sermão da Montanha (1979), apresenta ao público um ambiente de tensão. No centro de uma sala, Meireles empilhou dezenas de caixas de fósforos da marca Fiat Lux. As pilhas de caixas formavam um cubo de aproximadamente um metro e meio de altura, desta maneira, o "olho", símbolo que representa a marca, é repetido sequencialmente sublinhando o domínio da vigilância (Figura 3). Ao redor do cubo, cinco atores vestidos com roupas de guarda-costas "protegiam” a escultura inflamável. Como se estivessem armados, os homens permaneciam com uma das mãos encobertas dentro do paletó.

Nas paredes foram instalados oito espelhos com frases extraídas da passagem bíblica, Sermão da Montanha (Mateus 5: 1-12). O piso foi revestido com uma superfície áspera, de acordo com Scovino (2009, p. 9), "o ruído dos pés dos seguranças sobre as lixas que recobrem o chão lembra o som do fósforo sendo acesso na caixa, de tal modo que sua própria vigilância, longe de tranquilizar, gera ansiedade e medo." Vale lembrar que, diferente de La Menesunda, que foi realizada no ano anterior ao golpe de 1966 na Argentina, Fiat Lux foi apresentada durante a

${ }^{12}$ Ambientação composta por balões prateados em forma de travesseiro. Os balões são inflados com gás hélio e, portanto, flutuam no espaço. 
ditadura militar no Brasil, e, portanto, seus significantes estão diretamente relacionados aos anos de chumbo.

Figura 03 - Cildo Meireles, Fiat Lux: O Sermão da Montanha (1979

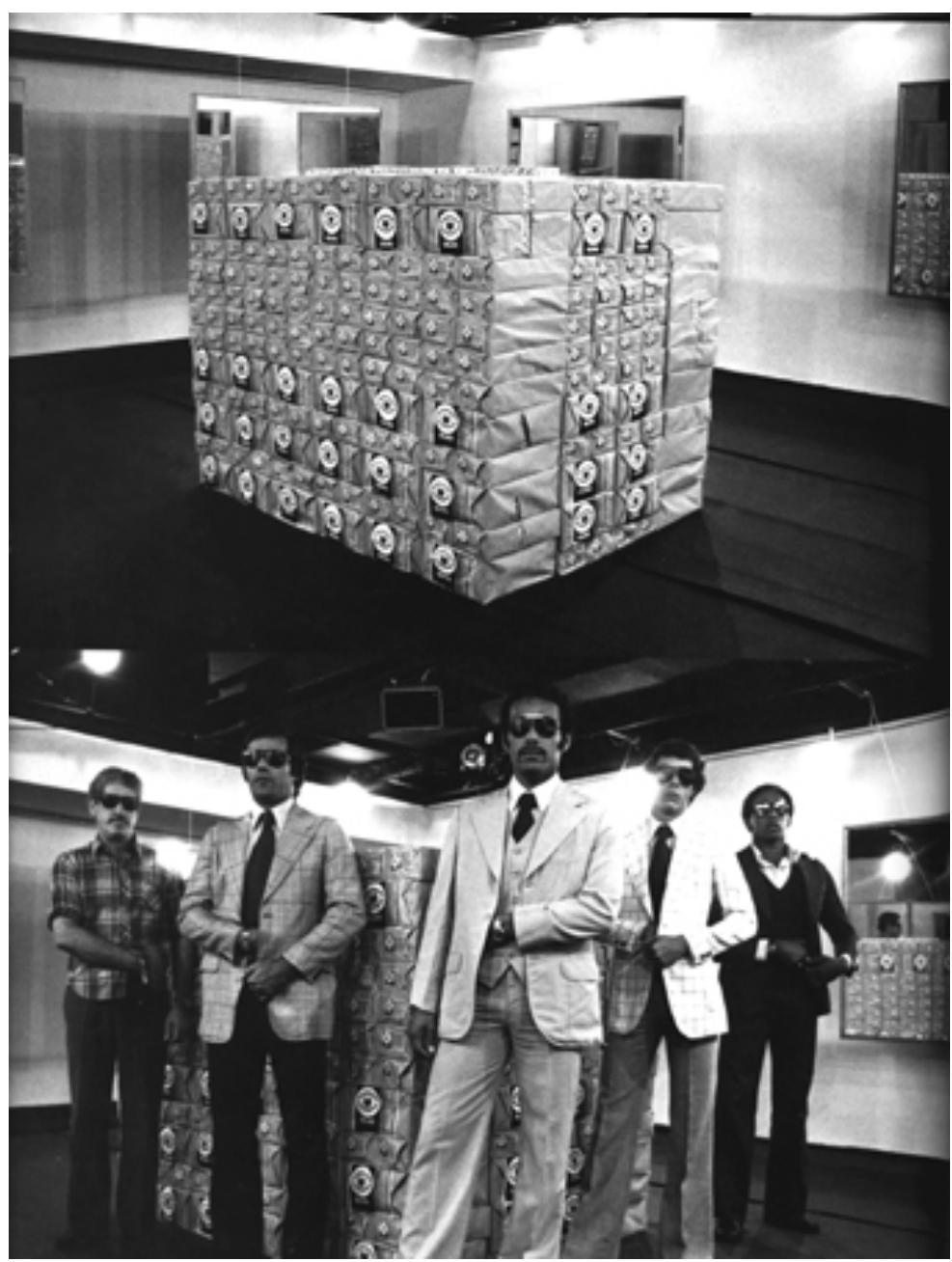

Fonte: https://anarquiabarbarie.wordpress.com/2014/11/12/arte-e-resistencia-cildomeireles-nos-anos-70/. Acesso em: 24 jun. 2020.

Ademais dos símbolos visuais, a lixa que forra o piso de Fiat $L u x$, ao ser friccionada pelos sapatos dos espectadores e dos performers, torna-se um elemento tátil e sonoro. Neste ambiente multisensorial, o público vivencia uma atmosfera de vigília que articula ficção e realidade. Isto porque, apesar dos atores representarem figuras de poder e simularem o porte de armas, a possibilidade de um incêndio era um risco real, visto que "o número de caixas de fósforos foi calculado por Meireles em quantidade suficiente para explodir a galeria" (Scovino, 
2009, p. 166).

\section{Sin Titulo (Habana, 2000) - Tania Bruguera}

Assim como Meireles, a artista cubana Tania Bruguera nos oferece uma experiência artística pautada no jogo de significantes e no contexto político de seu país. Sin Titulo (Habana, 2000) foi apresentado pela primeira vez no ano 2000 na Bienal de Havana, ocasião na qual o trabalho foi censurado por seu conteúdo político. Dezoito anos depois, Bruguera reconstrói Sin Titulo no MoMA - Museu de Arte Moderna de Nova York, a estrutura do trabalho era constituída de um ambiente único, um túnel, o qual era preciso aguardar horas em uma fila para ingressar. A espera faz parte da experiência que Bruguera propõe, em plena Manhattan o público toma consciência da vivência cotidiana de milhares de cubanos, ou seja, o enorme tempo gasto em filas.

Era permitida a entrada de cinco pessoas por vez, a medida que iam saindo, outras pessoas eram autorizadas a entrar. O tempo de permanência no espaço era livre, cabendo ao espectador a decisão da duração da assistência. Dentro do túnel havia pouca luz e era preciso caminhar devagar, o chão estava coberto de bagaços de cana de açúcar, gerando um ambiente de textura e odor singular. No centro do túnel, quatro performers nus realizavam uma partitura corporal, gestos com as mãos e os braços (Figura 4).

Também no centro do túnel, instalado no teto, um televisor antigo reproduzia o vídeo em preto e branco de um discurso de Fidel Castro, no qual o líder da Revolução Cubana abre a camisa para mostrar que não está usando um colete à prova de balas. Bruguera justapõem homens desnudos à imagem televisionada de Fidel que desnuda-se em um entorno protegido.

El publico es testigo de la transformación de estas figuras invisibles que protegen la aparición fantasmal de un líder que se ve solo a través de imágenes descompuestas de los medios de comunicación. Los cuerpos se convierten en marionetas irracionales con alma vacías, en esclavos de 
su proprio compromiso [...]. Los visitantes son observadores privilegiados porque pueden macharse. (Bruguera, 2018, p. 6).

A respeito da concepção de Sin Titulo, Bruguera revela que buscou realizar uma "obra-de-arte-total". Como um nó borromeano ${ }^{13}$, performance, instalação e vídeo estão integrados de modo que, se desassociados, perde-se o sentido do todo. No espaço, a atmosfera criada pela artista mescla um conjunto de estímulos sensoriais: texturas, odores, corpos desnudos, discursos políticos, iluminação sombria. Diferente dos performers em La Menesunda e Fiat Lux, os homens em cena não interagiam com o público, permaneciam repetindo a partitura corporal sem olhar ou dialogar com os presentes, dirigidos pela artista para representarem as "marionetes" do sistema.

Figura 04 - Tania Bruguera, Untitled (Havana, 2000) (versão de 2018

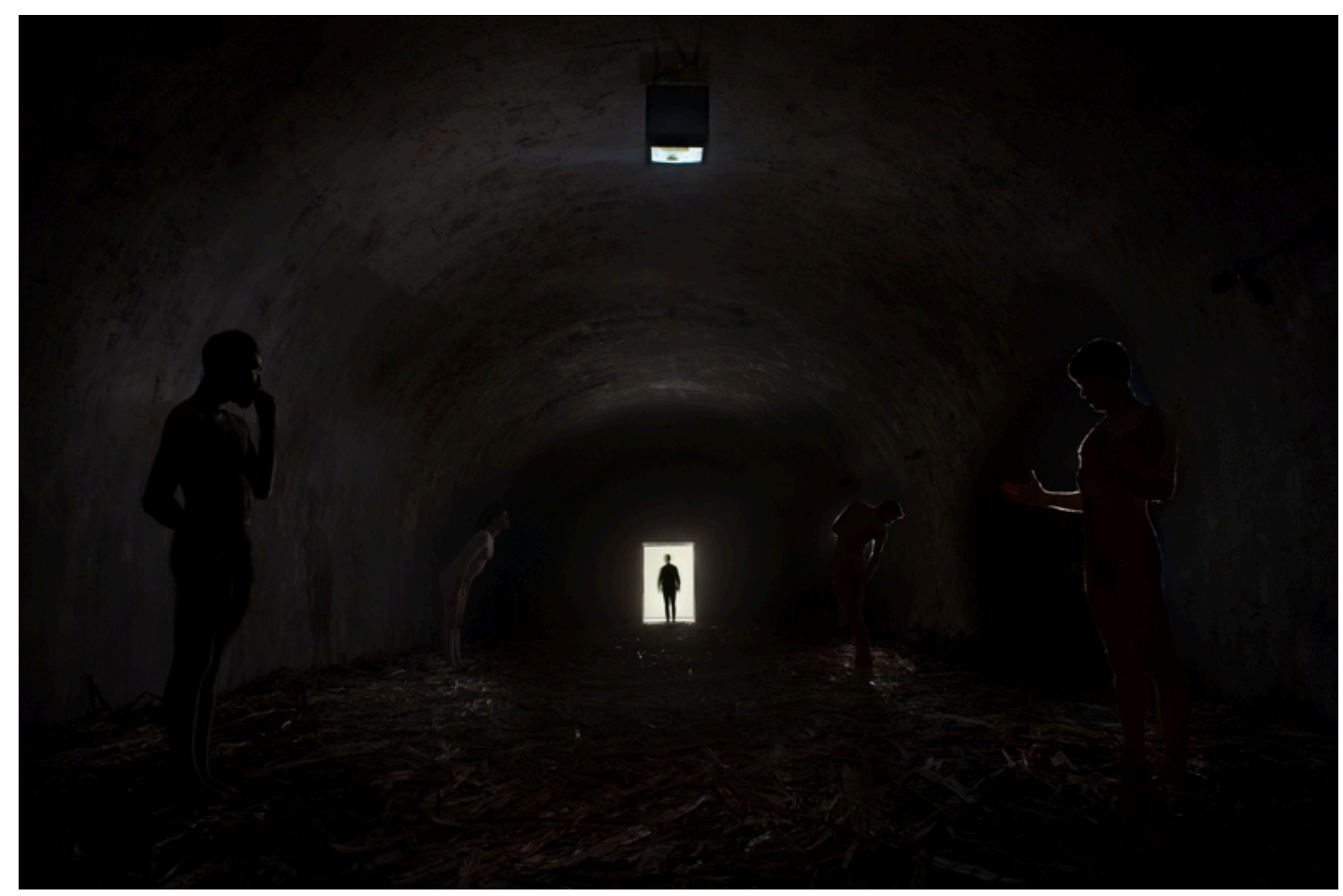

Fonte: https://www.moma.org/calendar/exhibitions/3898?installation image index=13. Acesso em: 24 jun. 2020

${ }^{13}$ Figura topológica composta por três aros entrelaçados, que, ao ser removido qualquer um dos aros, a ligação do conjunto se desfaz. 
Tanto Meireles, como Bruguera, executaram seus projetos em um contexto de regime autoritário e, ambos artistas adotaram uma postura de crítica aos sistemas antidemocráticos de Brasil e Cuba. Neste sentido, podemos pensar a imersão dos espectadores como uma estratégia de engajamento do público, contudo, diferente do projeto wagneriano - que se fundamenta no mito e na música, no apelo aos sentidos da visão e da audição do espectador - Meireles e Bruguera comunicam por meio da experiência fenomenológica, onde não há um mito a ser representado, mas um espaço a ser vivenciado e interpretado.

Diante do totalitarismo, observamos uma postura subversiva dos artistas latino-americanos. Por outra parte, Groys (2015, p. 210) identifica nos artistas soviéticos pós-modernos, entre eles Kabakov, uma atitude de complacência, "profundamente ancorada no idílio comunista - ela o privatiza e o expande em vez de renunciar a ele. É por isso que a arte pós-comunista parece ser tão inofensiva, isto é, nem crítica, nem radical o suficiente." Quiçá porque, diferente da União Soviética, a América Latina não vivenciou um projeto histórico e utópico de arte. Havia violência, perseguição política, censura e outros desmandos que cerceavam a liberdade artística e intelectual, sem embargo, não houve um programa ideológico tal qual a Gesamtkunstwerk Stalin ${ }^{14}$.

\section{Under de sí - Diego Bianchi e Luis Garay}

Por fim, Under de sí (2013), do artista argentino Diego Bianchi em parceria com o coreógrafo colombiano Luis Garay, apresentado na / Bienal de Performance de Buenos Aires (2015), foi definido por seus autores como "instalação, performance, projeto de teatro". O trabalho foi apresentado em um grande galpão do Centro de Arte Experimental da UNSAM - Universidad Nacional de San Martin. Logo na entrada era preciso passar por cima dos corpos dos performers, que,

\footnotetext{
14 Termo cunhado por Boris Groys (2008) para definir o “regime estético autoritário” de Stalin, que ambicionava um "novo mundo" para o povo soviético. "El hombre soviético no vivió en esos años dentro de la realidad, sino dentro del arte.” (Groys, 2008, p. 13)
} 
deitados no chão, sustentavam uma grande tábua de madeira para que os transeuntes pisassem em cima $^{15}$. O espaço era saturado de estímulos, os espectadores podiam caminhar livremente e explorar o tempo que desejassem.

No centro do galpão havia um grande aquário de vidro translúcido, onde as pessoas podiam fumar (Figura 5). Por todas as partes, escombros, destroços, entulho, restos de isopor, plástico, espuma, luzes e corpos espalhados que mesclavam-se a tênis da Nike, iPhones e até mesmo uma máquina de bronzeamento artificial. Em Under de Sí, o ambiente opera como caricatura de uma sociedade superficial e consumista. Os performers, em seus movimentos coreografados e repetitivos, não interagiam diretamente com o público, estavam, propositalmente, reduzidos a condição de objetos, ou, sujeitos-sujeitados.

Assim como Sin Titulo (Habana, 2000), mas a partir de outro enfoque discursivo, a escolha dos performers de ignorar a presença do público condiz com a narrativa proposta. Bianchi e Garay tratam da vaidade humana, na qual essa cena caótica e insalubre corporifica texturas, odores, cores e sensações do "under de sł" da nossa condição pós-moderna. Por meio do ambiente imersivo os corpos dos espectadores são incorporados ao trabalho, endossando essa massa de sujeitos "sujeitados". Logo, a imersão é uma estratégia de, literalmente, situar os espectadores como entes que habitam esse ambiente precário, isto é, não apenas expectam, de fora, os vícios da sociedade, mas, de dentro, seus próprios vícios tornam-se parte desse universo. Com isso, podemos concluir que o público não sai ileso, pisa em corpos, tira selfies, polui o ar e se encontra, de certa forma, impotente ou complacente no espaço.

${ }^{15}$ Vídeo-registro de Under de sí. <https://www.youtube.com/watch?v=zOYwFa5tkzk>. Acesso em: 24 jun. 2020. 
Figura 05 - Diego Bianchi e Luis de Garay,

Under de sí(Bienal de Performance de Buenos Aires, 2015

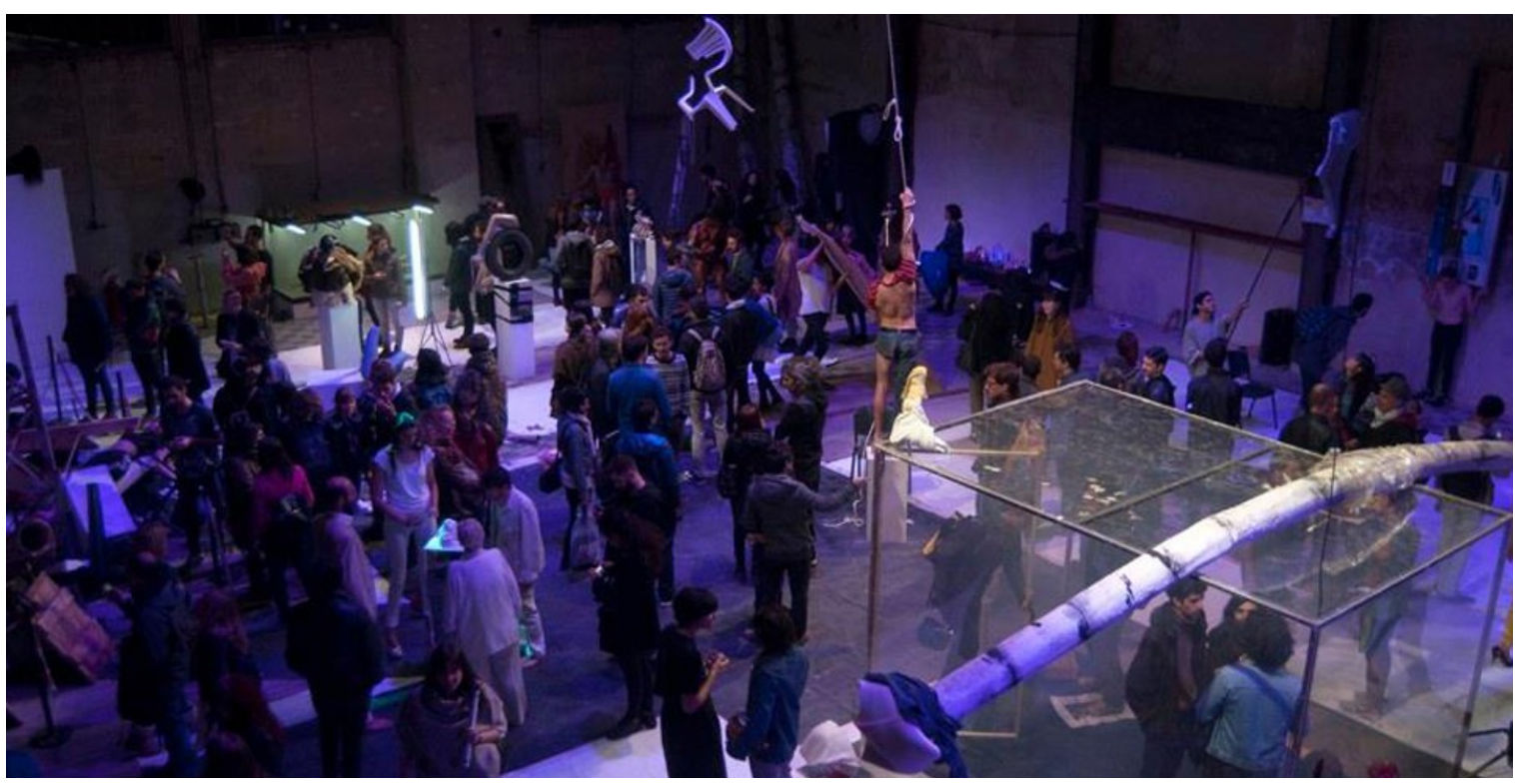

Fonte: < http://bienalbp.org/bp15/es/under-de-si/ > Acesso em: 24 jun. 2020.

Garay e Bianchi nos dão o ambiente cênico para explorar e ocupar, apesar das vivências subjetivas e individuais, a integração entre público, espaço e performers se dá coletivamente. Destaca-se que, nos quatro trabalhos descritos, a duração da experiência é relativa, ou seja, depende do tempo que o visitante decide permanecer no ambiente espetacularizado. Em outras palavras, a composição cenográfica e a partitura corporal dos performers podem ser assistidas por horas ou segundos, um modelo subjetivo que varia de espectador para espectador, similar a dinâmica de fruição da pintura e da escultura, não obstante, no âmbito de um acontecimento efêmero.

Sendo assim, no campo da cena performativa, a "obra total" instaura uma lógica distinta de fruição, pautada na descoberta do espaço pelo espectador. Ressalta-se que não é somente a imersão do espectador que determina essa vivência, mas a compreensão de que o trabalho se sustenta na permanência do "sujeito-perceptivo" no espaço. Por essa razão, ainda que encenações como Kordian, de Grotowski, diluam a fronteira que divide palco e plateia e situem o 
espectador dentro da cena, a duração do acontecimento teatral é determinada pelo tempo da ação dos atores. Por outra parte, nos trabalhos analisados, o tempo de ação dos espectadores é o que determina a duração da experiência

\section{Referências}

ARTAUD, Antonin. O Teatro e o seu Duplo. São Paulo: Editora Max Limonad, 1984.

BARRIO, Miguel Ángel González. Utopías e Realidades: revolución, Gesamtkunstwerk, drama musical. In: WAGNER, Richard. Ópera y Drama. Madrid: Akal, 2013.

BISHOP, Claire. Installation Art: A Critical History. London: Tate Publishing and Routledge, 2005.

BROCKETT, Oscar G; BALL, Robert G; FLEMING, John; CARLSON, Andrew. The Essential Theatre. Boston: Cengage Learning, 2017.

BRUGUERA, Tania. Tania Bruguera: Untiled (Havana, 2000) / MoMA. New York: Museum of Modern Art, 2018.

CAMARGO, Roberto Gill. Função Estética da Luz. São Paulo: Perspectiva, 2012.

DANTO, Arthur. O Abuso da Beleza. São Paulo: Martins Fontes, 2018.

EDER, Rita. Dos aspectos de la obra de arte total: experimentación y performatividad. In: EDER, Rita (Org.) Desafío a la Estabilidad: procesos artísticos en México 1952 - 1962. México: Universidad Nacional Autónoma de México / Turner, 2014.

FÉRAL, Josette. Além dos Limites: teorias e práticas do teatro. São Paulo: Perspectiva, 2015.

GROTOWSKI, Jerzy. Em busca de um Teatro Pobre. Rio de Janeiro: Civilização Brasileira, 1992.

GROYS, Boris. Obra de Arte Total Stalin. Valencia: Pre-Textos, 2008.

GROYS, Boris. Arte Poder. Belo Horizonte: Editora UFMG, 2015.

HUIZINGA, Johan. Homo Ludens: o jogo como elemento da cultura. São Paulo: Perspectiva, 2019. 
JODOROWSKY, Alejandro. Hacia el Efímero Pánico o jSacar al Teatro del Teatro!! México: El Gran Pan, 1981.

KABAKOV, Ilya. Sobre la Instalación Total. Ciudad de México: COCOM Press, 2014.

KAPROW, Allan. Notes on the Elimination of the Audience (1966). In BISHOP, Claire. Participation. London: Whitechapel/Cambridge: MIT Press, 2006.

KAPROW, Allan. Essays on the Blurring Art and Life. Berkeley: University of California Press, 1993.

MERLEAU-PONTY, Maurice. Fenomenologia da Percepção. São Paulo: Martins Fontes, 2018;

MINUJíN, Marta. Marta Minujín: happenings e performances. Ciudad Autónoma de Buenos Aires: Ministerio de Cultura del Gobierno de la Ciudad Autónoma de Buenos Aires, 2015.

ORTEGA Y GASSET, José. A Ideia do Teatro. São Paulo: Perspectiva, 2014.

RAMOS, Luiz Fernando. Mimesis Performativa: a margem de invenção possível. São Paulo, Annablume, 2015.

SCOVINO, Felipe. Negócio arriscado: dispositivos para um circuito da ironia na arte contemporânea brasileira. Revista Poiésis, Niterói, n.13, p.159-172, 2009.

WAGNER, Richard. La obra de arte del futuro. València: Universitat de València, 2000.

WAGNER, Richard. Arte y Revolución. Madrid: Cassimiro Libros, 2013.

Recebido em: 23/06/2020

Aprovado em: 31/07/2020 